\title{
Internet Use by Jordanian English Major Students and their Perception of Internet English
}

\author{
Dr Richard Lingwood (Corresponding author) \\ Al Isra University, PO Box 22, Amman 11622, Jordan \\ Tel: 96-2-6471-1505 E-mail: richardlingwood@gmail.com \\ Dr Riyad F Hussein \\ Middle East University for Graduate Studies, PO Box 42, Amman 11610, Jordan \\ E-mail: rfhussein@hotmail.com
}

Received: December 26, 2011

Accepted: January 21, 2012

Published: June 6, 2012

doi:10.5430/elr.v $\ln 1 \mathrm{p} 50$

URL: http://dx.doi.org/10.5430/elr.v1n1p50

\begin{abstract}
This study investigates students' use of CMC on the Internet. It explores students' perception of Internet English. The questionnaire elicited data on access and frequency of $\mathrm{CMC}$, the nature of Internet English and the effect of Internet English on Standard English. Results showed half the participants chatted and emailed regularly, and social CMC was believed to be a useful learning resource. The level of error in synchronous CMC was perceived to be higher than in offline writing. Error correction needs to be consolidated, but CMC is likely to improve overall competence in Internet and Offline English. Specific further research is recommended.
\end{abstract}

Keywords: Computer mediated communication, CMC, ELT, Netspeak, Online English

The internet hosts changing and varied fora, including email, elearning, chatgroups, virtual worlds, blogging, instant messaging, and social media sites like Facebook and Twitter. (Crystal, 2010b). Some people think the internet is homogeneous, encompassing only one set of activities or situations. In fact the internet is a diverse and mutable social construct. It is rebuilt as it is used.

In the past Jordanian students studied English, and its idioms and cultural context, in order to speak face-to-face or on the telephone with US or UK native speakers, or to write letters to them or read letters from them. Now, they may need International English as a Lingua Franca in order to speak to Chinese or Indians or Russians who also have learnt English. They will often use English to communicate with other educated Arabs. Now, they will spend significant time in CMC using Internet English. In their later life CMC will be used for students' personal and business communications. Thus a gap is widening between the English they learn at university and the language they will use after university. The linguistic consequences of the evolving digital revolution will be far reaching. It is of value to investigate students' use of the internet and their perception of change in the linguistic properties of Netspeak.

\section{Literature Review}

\subsection{Features of Internet English}

There is a wealth of academic discussion about Netspeak as it evolves in US, UK and World Englishes. Crystal (2004) delineated Netspeak and its varied orthographic, graphic, grammatical, lexical, and discourse features. David Crystal's Language and the Internet (2006), accelerated academic debate about the evolving nature of different Netspeaks, from which the definitions and conceptual framework of this paper are primarily derived. Extensive discussion continues, for example, with Hadžiahmetovi-Jurida's 'Some distinctive lexical properties of Netspeak' (2007) and Crystal's 'Internet language', in The Pragmatics Encyclopedia (2010a). Prøysen (2009) explored the fear that Netspeak will leak into Offline English and corrupt it.

Internet English is a subset of computer mediated communication (CMC) and digitally-mediated communication (DMC), and has unique features of its own. It has a special lexis, like lurking, flaming, and spamming. Hard af Segerstad (2002) delineated three factors that affect the language of CMC: synchronicity, means of expression, and 
situation. She classified the modes of CMC into two groups: firstly, synchronous, web chat and instant messaging, and secondly, asynchronous, email and SMS. She concluded that the quality of language used in synchronous and asynchronous interaction was not deteriorating and the language variety used generally fitted the situation in which it occurred. She thought educationalists and linguists should be aware of changing language registers on the internet.

Baron (2010) thought Internet English is not identical to speech or writing but displayed properties of both. Emails, chatgroups, visual worlds, and instant messaging display several of the properties of speech although expressed through the medium of writing. Chatting demands a response with spontaneity and speed. They are transient because messages may be forgotten or deleted. Davis and Brewer (1997) reported that online discourse is writing that often reads as if the sender were writing down speech. Crystal (2010a) noted that turn taking in chat is similar to speech but overlapping turns may lead to chaotic interaction unlikely to be tolerated in ordinary speech. Crystal (2011) predicted that in the next twenty years speech-to-text and text-to-speech automatic translation will lead to new forms of Netspeak.

\subsection{The Effect of Internet English on Offline English}

There is extensive academic discourse on the effect of Netspeak on written US, UK and World Englishes by different types of user. Specialist journals, for example, the Computer Assisted Language Instruction Consortium Journal (CALICO Journal), or the Journal of Computer-Mediated Communication (JCMC), host discussion about Netspeak and its relation to Offline English. Beauvois and Eledge (1996) found that foreign language learners benefitted from CMC when they had time to review and edit emails. Gonzalez-Bueno (1998) suggested that English language learners make progress during the process of writing emails in English because they have more time to edit and develop the complexity and competence of their language than when writing in other situations.

The effect of Internet English on Offline English can be summarized under three heads. Firstly, emergence of a relaxed attitude towards the use of Standard English forms due to tolerance of deviations whether in structure, lexis, or spelling. This is evident in the number of misspellings and the deviation from Standard English grammar. Secondly, there may be an increase in the use of symbols, ellipsis, dots and abbreviations. Capitalization may be neglected. There may be repeated use of commas and less than discriminate use of punctuation. Punctuation may be minimal and sometimes is completely lacking. These two features may leak into Offline English.

Thirdly, the growth of Netspeak experimentation with the language and the freedom to coin new words, acronyms, and language patterns may result in crossover into Offline English. Some new forms result from the practice of joining words or phrases without spaces, and capitalizing the words within the compound, for example: NetLingo, CamelCase, and iMac. CamelCase joins words or phrases without spaces and capitalizes the words within the compound.

Although Crystal and other linguists observe and report the use of Netspeak innovations, there is debate on its effectiveness in meeting the writer's aims online and offline. Dan Meyer (2009) and the online discussion of the data in his article 'Netspeak Won't Get You A Date', explored his findings that more potential dates responded to online messages written in correct Standard English than replied to messages written in Netspeak with the innovative features of Internet English. This suggests that even online Netspeak innovation is not universally applauded, and its leakage into Offline English may never access some areas.

Baron (2011) wrote that the debate about the damage done to offline English by CMC is nearly over and there is little evidence of damage.

Much ink (actual and virtual) has been spilled over the question whether the language used in computer-mediated communication or on mobile phones (particularly regarding texting) is undermining traditional written language (see Thurlow 2006). Empirical research suggests that when it comes to the more obvious features of language such as spelling, syntax, and even lexicon, the answer is largely "no" (Baron 2004, 2008; Crystal 2008).

However, language will continue to change as a result of the interplay of social change and technological developments. It may be that conventional written English as we now know it may continue, but just as one of many forms, alongside other modes of communication which develop in ways we do not yet know.

Internet English could have negative implications for Jordanian English major students as they may neglect the use of correct grammatical constructions, the conventions of formal writing, and the polite norms of usage. They may use informal and inaccurate English in situations which require the use of a formal register. To generalize, it may be that the keyboard generation is more tolerant of grammatical, spelling and punctuation errors. Perhaps they do not care much about language forms but care more about content and meaning. The speed of writing and pressure to 
respond quickly when interacting in synchronous CMC may develop habits which transfer into Offline English where they are less appropriate.

This study examines the effect of internet use on written English of Arabic speaking students of L2 English at Jordanian universities. There is one study of students' perception of the effect on English language acquisition of internet usage by students of English in Jordan: Mahfouz (2010) found that a significant number of Jordanian university students believed that the use of the internet helped them to improve their writing skills. There are few studies available on the effect of CMC on the written English of English majors at Arab universities.

\subsection{Questions of the Study}

The study investigates computer use by English major students in Jordan and how it affects their English. It explores their perception of Internet English. The researchers designed a questionnaire to find answers to three questions.

1) What is the extent of use of the internet and CMC by English major students?

2) What is the effect of the main features of Internet English on university students' English?

3) What perception do English major students have of Internet English?

\section{Method}

\subsection{The Sample}

The sample consisted of one hundred and eighty undergraduate English major students from two private universities in Amman, Jordan. One hundred and four were undergraduates from Al Zaytoona University and seventy six were undergraduates from the Middle East University for Graduate Studies (MEU). MEU offers both undergraduate and graduate courses. However, twenty eight of the questionnaire forms were discarded because they were not completed or were filled out carelessly. This left one hundred and fifty two questionnaires for analysis. Females constituted $52.3 \%$ of the sample, and males $47.7 \%$. The students were aged from 18 to 24 . The majority of the participants were aged 20 or 21 years old, so most were either juniors or seniors. For the sake of convenience, entire classes from departments of English and Translation at both universities were surveyed.

\subsection{Research Instrument}

The researchers developed a questionnaire consisting of three sections totaling 43 questions. The first section included six questions and elicited biographical data such as age, gender, year of study and college affiliation. The second section of 15 questions elicited data on student access to the internet and use of CMC. The third section of 22 items asked about students' perception of CMC. Seven questions $(1,5,6,10,13,15$, and 21) asked about students' perception of Internet English. Eleven items (2, 7, 9, 11, 12, 14, 16, 18, 19, 20, and 22), asked students to comment on online users in general. Four items, (3, 4, 8, and 17), elicited data on the impact of Internet English on Standard English.

\subsection{Validity of the Instrument}

The researchers asked a panel of experts in linguistics and information technology at MEU to establish the validity of the questionnaire. The questionnaire was modified in response to the comments and suggestions made by the jurors.

\subsection{Limitations of the Study}

Some useful analyses were not made, for example, of gender difference, as this would require a different and comprehensive research method. The researchers would value access to genuine samples of chatting in English by Jordanian students to analyze them and provide evidence. Analysis of chatting samples can be undertaken in another research project.

\subsection{Data Analysis}

The students were asked to mark an $x$ in one of the columns next to each statement about opinion. If a student 'strongly agreed' he or she was instructed to mark an $x$ in the first column; if $\mathrm{s}(\mathrm{he})$ 'strongly disagreed' then $\mathrm{s}(\mathrm{he})$ was instructed to mark an $x$ in the last column, and so forth. The researchers identified, categorized and interpreted the data using percentages and frequencies.

\section{Results}

\subsection{What is the extent of use of the internet and CMC by English major students?}

Section two, question 1, asked about internet access. Nearly three-quarters of the students, $73 \%$, indicated they had access to the internet at home. Outside the home $13.5 \%$ had access at an internet café and $8.5 \%$ had access at their 
university. Only $5 \%$ needed to access the internet elsewhere. Internet access seems to be good for these students. Question 2 asked students to rank their internet activity. The internet is mainly used for emailing by $30 \%$ of the students; $32.2 \%$ used it mainly for chatting; $32.1 \%$ mainly for accessing search engines; $4.1 \%$ mainly for instant messaging and lastly, $1.4 \%$ mainly for blogging. Information retrieval was a significant activity for nearly one third of the participants. Just under two-thirds, $62.2 \%$, used the internet mainly for emailing or chatting.

In question 3, students were asked about the type of email accounts they had. The majority, $52.2 \%$, indicated they had a Yahoo account, 40.7\% a Hotmail account, 5\% a Gmail account and 2.1\% had other types of account. This shows that Yahoo accounts ranked first followed by Hotmail and finally Gmail. Yahoo and Hotmail offer click in static emoticons on the toolbar: only Gmail offers kinetic emoticons. Question 4 elicited data on the people to whom students write electronic messages. Just over two-thirds, $67.5 \%$, indicated they write emails to their friends, $18.6 \%$ to their relatives, $6.4 \%$ to companies and corporations, $3 \%$ to pen pals and finally $4.5 \%$ to other unnamed parties. Thus at $89.1 \%$, email use for this group was predominantly social. In question 5 , students were asked to state the length of time they have had an email account. More than half, 52.1\%, indicated they had an email account for four years or more, $22.2 \%$ for three years, $9.3 \%$ for two years, and $16.4 \%$ for one year. More than $90 \%$ of the participants were experienced email users.

\subsection{What is the effect of the main features of Internet English on university students' English?}

Table 1 gives the results calculated as percentages. Question 6 asked how often students checked their email for grammatical correctness: $34.4 \%$ stated 'rarely', $22.7 \%$ stated 'never', $21.1 \%$ stated 'often', $14.4 \%$ stated 'sometimes' and $7.7 \%$ stated 'always'. Thus more than half, $57.1 \%$, rarely or never checked their emails for grammatical correctness. Only $22.1 \%$ regularly checked their emails for grammatical correctness. Question 12 asked if students checked for grammatical correctness when chatting. Under a third, $31.6 \%$, indicated 'never', just over a quarter, $26.6 \%$, 'rarely', $19.3 \%$ 'sometimes', $12.2 \%$ 'often', and $10.4 \%$ 'always'. Well over half, $58.2 \%$, paid little or no attention to the correction of grammatical mistakes when chatting. This may be because chatters are under time pressure in synchronous communication.

Responses to question 7 showed that just under a third, 32.8\%, 'rarely' checked email messages for spellings, 21.5 'never', $22.8 \%$ 'sometimes', $15.3 \%$ 'often' and 7.7\% 'always'. In summary, more than half, $54.3 \%$, either 'rarely' or 'never' checked spelling while writing emails. Less than a quarter, $23 \%$, regularly checked spelling while writing emails. Question 13 asked if students checked for spelling and punctuation errors while chatting. Nearly two-thirds, $63.8 \%$, stated 'never', or 'rarely', $16.1 \%$ stated 'sometimes', $11.6 \%$ stated 'often', and $8.3 \%$ stated 'always'. In summary, in synchronous chatting it seems well over half did not regularly check for grammatical errors, and nearly two-thirds did not regularly check for spelling or punctuation errors.

Responses to item 8 showed that $37.8 \%$ 'rarely' used acronyms and abbreviations in emailing, $19.4 \%$ 'never', $5.5 \%$ 'sometimes', 25\% 'often' and 12.2\% 'always' used acronyms and abbreviations. More than half of the students, 57.2\%, rarely or never used acronyms or abbreviation in emailing. The more frequent use of acronyms or abbreviation in chatting than in non-synchronous emailing may be caused by the urgent need to respond when chatting.

Questions 9 to 15 asked about the use of chat rooms; programs used in chatting; the amount of time spent in chatting, and the nature of the language of chatting from the students' perspective. Question 9 addressed the length of time students have been engaged in chatting and entering chat rooms: $25 \%$ per cent indicated they had been chatting for one year; $57 \%$ for two years; $8.1 \%$ for three years, and $9.2 \%$ for four years or more. Almost all students, $99.3 \%$, engaged in chatting at some time, and three quarters had more than one year's experience of chatting.

Question 10 asked about the instant messaging programs that students used: 52.8\% reported they used Yahoo Messenger; $40.7 \%$ used MSN chat rooms; and the rest, 6.5\%, used other programs such as Paltalk and ICQ. Responses to question 11 which elicited data on the amount of time spent in chatting each week, showed that $52.6 \%$ spent two hours or less, $17.5 \%$ three hours or less, and $7.6 \%$ four hours or less, and $22.3 \%$ five hours or more. These responses show that all students had taken part in chatting, and nearly half, $47.4 \%$, spent more than two hours a week chatting.

Acronyms and emoticons are a notable feature of Chatspeak. In response to question 14 which asked about the frequency of use of acronyms and abbreviations while chatting, 30.1\% stated 'always', $22.2 \%$ stated 'often', $18.3 \%$ stated 'sometimes', $15.5 \%$ 'rarely', and 13.9\% stated 'never'. More than half, 52.3\%, used acronyms and abbreviations during chatting. The use of these acronyms and abbreviations is believed to save time and to show the writer to be familiar with useful communication tools. Only $29.5 \%$ stated they 'rarely' or 'never' use this tool. In part this may be attributed to some students' recent introduction to the experience of chatting. Question 15 asked about the extent of 
using emoticons or smileys in chatting. The response was polarized as $42.4 \%$ stated they 'always' or 'often' use emoticons in chatting and about one third,32.1\%, stated they 'rarely' or 'never' use emoticons in chatting. The remaining quarter, $25.3 \%$, stated they 'sometimes' use emoticons.

\subsection{What perception do English major students have of Internet English?}

The third section of the questionnaire comprises 22 items intended to discover students' opinion about Internet English. The researchers will discuss these opinions under three subheadings. Firstly, perception of the nature of Internet English, comprising items 1, 5, 6, 10, 13, 15, and 21. Secondly, opinions about the use of Internet English by users online, comprising items $2,7,9,11,12,14,16,18,19,20$, and 22. Thirdly, perception of the influence of Internet English on Offline English which comprises items 3, 4, 8, and 17. Table 2 summarizes the students' responses as percentages.

3.3.1 Perception of the nature of Internet English. Item 1 showed that three-quarters of the students, $75.4 \%$ of the sample, either 'agreed' or 'strongly agreed' with the statement that 'Internet English allows for greater creativity and expression'. They believed that Internet English, compared with writing offline, is a source of innovation and creativity. This is supported by responses to item 21 where $58.3 \%$ believed that Internet English will produce new language registers. Responses to item 10 showed that $44.3 \%$ subscribed to the notion that Internet English is more rich and dynamic. Item 15 showed that two-thirds of the participants, $65.4 \%$, believed Internet English creates new language forms.

Item 5 asked for responses to the statement, "while chatting or emailing, typing speed leads to errors in the use of English forms". Whereas 71\%'agreed" or 'strongly agreed', only $11.1 \%$ either 'disagreed' or 'strongly disagreed'. This supports the belief that typing speed is responsible for errors in the use of English forms. It also implies that a nearly three-quarters of students believe it is in the nature of Internet English that, if assessed according to the criteria of Standard English, there will be more errors.

Item 6, asked students whether Internet English is a 'hybrid of spoken and written English'. About two-thirds, 65.5\%, either 'agreed' or 'strongly agreed' and only $19.9 \%$ 'disagreed' or 'strongly disagreed'. Two-thirds of students believed that Internet English is a hybrid of writing and speech.

Item 13, asked for a responses to the statement 'Internet English is almost the same as Standard English but with slight changes'. Just over half, 51.6\%, either 'agreed' or 'strongly agreed': this shows that the differences from Standard English are not perceived to be significant by a slight majority. Over a third, 36.6\%, 'disagreed or 'strongly disagreed': this supports the idea that Internet English takes on a variety of forms in different CMC situations.

3.3.2 Perception of the use of Internet English by users online. Items 2, 7, 9, 11, 12, 14, 16, 18, 19, 20, and 22 asked for students' opinion about how people use Internet English. Responses to item 2, which stated that, 'in chatting and emailing, online users make grammar and spelling mistakes on purpose' showed nearly half disagreed, $47.7 \%$, and only just over a quarter, $27.1 \%$, expressed agreement. A majority of students believed that online users such as chatters, instant messagers and emailers make grammar and spelling mistakes, not on purpose but most likely due to their fast typing speed. Item 7, states, 'in emailing, chatting and instant messaging, online users make spelling mistakes due to the irregularity of the English spelling system'. Nearly three-quarters, 71\%, 'agreed' or 'strongly agreed', but only $11.1 \%$ either 'disagreed' or 'strongly disagreed'. This tends to support the idea that typing speed is responsible for spelling errors in Internet English. It is a significant interruption to interaction for an EL2 typist to reconsider irregular spellings, or check in a paper dictionary or make an online check.

Item 9, asked for students' opinion about the statement, 'Internet English users pay little attention to punctuation and capitalization', 56.6\% expressed agreement and 34.9\% disagreement. Although 56.6\%, the percentage of those who showed agreement or strong agreement is not a large majority, it does support the idea that a significant proportion of online users neglect punctuation and capitalization.

Item 11 stated, 'in chatting, online users use emoticons to make others understand them and their personality. Nearly two-thirds, $65.5 \%$, either 'agreed' or 'strongly agreed' and only a fifth, $19.9 \%$, 'disagreed' or 'strongly disagreed'. A significant majority of these students believed the use of emoticons contributes to the function of expressing oneself.

Item 12 states, 'using acronyms such as IMHO and BRB in chatting and instant messaging saves users' time'. A substantial $61 \%$ 'agreed' or 'strongly agreed', and only $17.7 \%$ 'disagreed' or 'strongly disagreed'. A significant majority believed that the frequent use of abbreviations and acronyms in chatting and instant messaging saves chatters' time and effort. 
Item 14 stated that, 'online users use new forms to show they are modernized and not traditional'. Nearly two-thirds, $65.5 \%$, 'agreed' or 'strongly agreed', but only $15.5 \%$ 'disagreed' or 'strongly disagreed'. It may be that Netspeak has some of the social cachet of the latest ipad or smart phone.

Item 16 is concerned with the statement, 'internet users use acronyms and emoticons to impress their counterparts': $16.6 \%$ 'agreed' and 42.2 'strongly agreed'. This shows that quite a high percentage of the participants, $58.8 \%$, thought acronyms and emoticons are used to impress the peer group.

Item 18 stated, 'the use of new forms is indicative of youth, intelligence, and ingenuity: $63.8 \%$ either 'agreed' or 'strongly agreed' and only $22.9 \%$ expressed their disagreement or strong disagreement. It seems a majority of students believed in their generation's creativity in new forms of Internet English.

Item 19 stated 'internet users misspell words in chatting and instant messaging due to typing speed'. Whereas $63.9 \%$ either 'agreed' or 'strongly agreed' only $18.2 \%$ expressed disagreement or strong disagreement. In chatting and instant messaging, writers are keen to respond quickly. Perhaps in synchronous communication people tend to focus more on the content they wish to convey and neglect Standard English conventions of writing and spelling.

Item 20 stated 'in chatting and emailing, users pride themselves on knowing a specialized language'. Two-thirds of the students, $64.9 \%$, 'agreed' or 'strongly agreed' and only $17.1 \%$ expressed disagreement or strong disagreement.

Item 22 stated, 'online users use acronyms such as IMHO and BRB, in chatting and instant messaging due to their deficiency in English spelling'. More than half, 58.3\%, showed agreement or strong agreement and nearly one third, $32.1 \%$, showed disagreement or strong disagreement. The response to item 12 suggested that acronyms are used to save time, but here their use is associated with poor competence in spelling. This seems to be an exception to the opinion expressed in response to item 18 that the use of new forms is indicative of intelligence.

3.3.3 Perception of the influence of Internet English on Offline English. Responses to item 3, which states that 'Internet English used in chatting and instant messaging has a negative impact on English grammar', showed that only a quarter, $24.9 \%$, 'agreed' or 'strongly agreed' and $54.9 \%$ 'disagreed' or 'strongly disagreed'. Only a quarter of students thought Internet English and chatting have a negative impact on English grammar.

Item 4 asked for students' responses to the statement, 'Internet English used in chatting and instant messaging has a negative impact on English spelling and punctuation'. More than half, 56.6\%, either 'agreed' or 'strongly agreed', while only $17.7 \%$ 'disagreed' or 'strongly disagreed'. More than three times the number of students thought Internet English corrupts Standard English, than those who thought it did not. Many students believed that Internet English has a negative impact on spelling and to a larger extent on punctuation. Item 8 asked for responses to the statement, 'Internet English will develop and upgrade the English language'. Whereas 58.3\% either 'agreed' or 'strongly agreed', only $22.1 \%$ 'disagreed' or 'strongly disagreed'. In general, although spelling and punctuation may suffer, many students thought the use of $\mathrm{CMC}$ on the internet would improve the English language.

Item 17 stated 'overuse of slang in chatting and instant messaging is distorting English'. Just over half, 52.2\%, either 'agreed' or 'strongly agreed' and $19.9 \%$ 'disagreed' or 'strongly disagreed'. Although the percentage of those who showed agreement or strong agreement is only just over half, it indicates the perceived negative impact of slang on Offline English.

\section{Discussion}

The data shows that this sample of Jordanian students have very good access to the internet. This makes them an exceptional group in a country with a low population penetration of internet use of $26.8 \%$ : this compares to $70.4 \%$ in Israel and 19.8\% in neighbouring Syria (Internet World Stats, 30 June, 2011). Irbid, a city in the north of Jordan with an unusually high concentration of students attending five universities, was reputed in 2000 to hold a world record for the number of internet cafes per capita (Weik, 2000). University Street in Irbid appears to consist almost entirely of internet cafes. Thus it may be that, as a group, students in Jordan who nearly all use CMC are different from most of the population.

Just under two-thirds of students used the internet extensively for emailing or chatting. Students predominantly used email and chatting to communicate with friends and family. The majority of students have had an email account for four years or more and are experienced users. Half of the students spent more than two hours a week chatting. As regular practice is an effective way of improving competence for EL learners, students think social CMC is not a waste of study time, but a useful learning resource.

Most students did not agree with the assumption that internet use, especially chatting, has negative impact on English grammar. Less than a half of students checked their emails for grammatical correctness. When chatting it seems well 
over half did not regularly check for grammatical errors. Regular practice will help the participants improve their grammar, but without an objective assessment of their competence to confirm this opinion it may be that improvement in grammatical accuracy remains a priority for some students.

A large majority adhered to the idea that internet use, especially chatting and messaging, has a negative impact on English spelling and punctuation. Nearly two-thirds did not regularly check for spelling, or punctuation errors when chatting. This suggests a need to support students who chat to review and correct their writing.

There is support for the belief that typing speed is responsible for errors and there will be more errors in Online English. To generalize, many students thought grammar and spelling mistakes are made, not on purpose, but due to their fast typing speed. A majority thought errors may be due to the irregularity of the English spelling system. It may be that $\mathrm{CMC}$ will lead to simpler spelling. Perhaps in Online English people tend to focus more on the content they wish to convey and ignore matters related to form, such as Offline English conventions of writing and spelling. Students thought that online users pay little attention to punctuation and capitalization. This suggests that Jordanian students need to prioritize accurate spelling and punctuation.

A majority of students believed that Internet English is a hybrid of writing and speech.They concur with Baron's findings (2011) except she writes that for her sample there is a significant gender difference in instant messaging (IM).

Taken as a whole, the IM conversations were more akin to face-to-face speech than to conventional writing. However, when data were analyzed by gender, male IM more closely resembled speech, while female IM conversations conformed more to written norms ( $\mathrm{p} 1)$.

Internet English takes on a variety of forms in different fora like tweeting, chatting, blogging, emailing and website use. The differences from Standard English were not perceived to be significant by a slight majority of students. If Online English is a hybrid of spoken and written English then daily activity on Facebook or Yahoo Messenger may develop the cognitive elements of speaking.

A slight majority of students thought Netspeak slang might distort Standard English. This seems to contradict the findings of Varnhagen et al. (2010) that, for their sample, new language does not have a harmful effect on conventional written language. Many thought online users use new forms to show they are up-to-date and impress their peers. Facility in the use of new forms of language may be seen as a source of pride by some students rather than a sign of deficiency in language competence. In general, students believed the use of new forms of CMC shows youth, intelligence, and ingenuity.

It was only with the use of the printing press at the end of the fifteenth century that a nationally standardized form of English emerged. The growth of CMC may create a standardized International English across the globe. It might create wide diversity alongside the standard form. English as a Lingua Franca may become diverse and mutable. Many Jordanian students believed that Internet English is a source of innovation and creativity. They believed it is rich and dynamic and creates new language forms. A majority believed that Internet English will develop and upgrade the English language. Whether this is a form of Arabic indigenized English remains to be seen.

The nature of the language used in CMC and its effect on the Offline English of EFL students is significant. The teaching of English language related subjects at many schools and universities prioritizes the use of the internet as this is the foremost channel for communication in English. This study suggests students believe it has a positive effect on Offline English. However, correct spelling and punctuation and elements of grammar may need to be reinforced. Language learners should be encouraged to use the internet as part of an integrated course which raises their competence online and offline.

International schools in this region foreground internet use across the curriculum from elementary level. Perhaps the Ministry of Education and the Ministry of Higher Education might consider a long term plan to promote skills and competencies in the use of Internet English and CMC in order to support economic growth and the general wellbeing of citizens. It is to be hoped that support may be given for evidence-based research to understand and promote effective $\mathrm{CMC}$ use in the Arab world so this can be integrated with English language teaching in schools and universities. At present this is a privilege reserved for students of costly private schools and colleges.

The opportunity for learners to edit their writing and the use of tools and searches to self-correct spelling, word choice, and grammar; the opportunity to listen to UK radio stations online; and the availability of translation tools, and of tools to practice speaking and listening, are only a part of the English language learning resources available online now. For example, if chatting is good practice for the conceptual element of speaking it may have value to develop fluency and as part of a program to support correct grammar use in speaking. Sadly, in Jordan at present, the 
internet may often be used to find material of doubtful value and relevance to be learnt by heart and indiscriminately reproduced in examinations. Social CMC use provides an opportunity for language learners to make communication in English a daily practice, however it is not yet fully integrated into the education system.

\subsection{Recommendations}

The researchers recommend that further research address five areas. Firstly, gender difference in Jordanian students' use of CMC. Secondly, the relationship between student use of CMC and Offline English competence. Thirdly, English major students' use of CMC compared to CMC use by students of other majors in their university. Fourthly, the level of competence in CMC among teachers in private and state schools and universities. Fifthly, utilization of the internet in English teaching at all levels.

\section{References}

Baron, N. (2004). See You Online: Gender Issues in College Student Use of Instant Messaging, Journal of Language and Social Psychology, 23, 397-423. http://dx.doi.org /10.1177/0261927X04269585

Baron, N. (2008). Always on: Language in an online and mobile world. New York, NY: Oxford University Press.

Baron, N. (2010). Are instant messages speech? In J. Hunsinger, L. Klastrup, \& M. Allen (Eds.), International Handbook of Internet Research. (pp. 1-22). http://dx.doi.org:10.1007/978-1-4020-9789-8

Baron, N. (2011). Control freaks: How online and mobile communication is reshaping social contact. Language at Work. Issue 7. [Online] Available: http://www.american.edu/cas/faculty/nbaron.cfm

Beauvois, M. \& Eledge, J. (1996). Personality types and megabytes: Students' attitudes toward computer mediated communication (CMC) in the language classroom. Computer Assisted Language Instruction Consortium Journal, 13(2 \& 3), 27-45. [Online] Available: http://calico.org/page.php?id=5

Crystal, D. (2004). A glossary of Net speak and text speak. Edinburgh: Edinburgh University Press.

Crystal, D. (2006). Language and the Internet (2nd ed.). Cambridge: Cambridge University Press. http://dx.doi.org/10.1017/CBO9780511487002

Crystal, D. (2008). Txtng: The Gr8 Db8. Oxford: Oxford University Press. Crystal, D. (2009). Texting: frNd or foe? The Linguist, 47 (6), 8-11.

Crystal, D. (2010a). Internet language, in L. Cummings (Ed.). The Pragmatics Encyclopedia (pp. 234-6). London: Routledge.

Crystal, D. (2010b). The changing nature of text: A linguistic perspective. In W. van Peursen, E. Thoutenhoofd, \& E. van der Weel, (Eds). Text comparison and digital creativity. (pp. 229-51). Leiden: Brill.

Crystal, D. (2011). O brave new world, that has such corpora in it! New trends and traditions on the internet. Plenary paper to International Computer Archive of Modern and Medieval English Conference, 32, Trends and Traditions in English Corpus Linguistics, Oslo, June 2011.

Davis, B. \& Brewer, J. (1997). Electronic discourse: Linguistic individuals in virtual space. Albany, NY: State University of New York Press.

Gains, J. (1998). Electronic mail - A new style of communication or just a new medium: An investigation into the text features of email. English for Specific Purposes, 18 (1), 81-101. http://dx.doi.org/10.1016/S0889-4906(97)00051-3

Hadžiahmetovi-Jurida, S. (2007). Some distinctive lexical properties of Netspeak. Jezikoslovlje, 8 (2), 193-210.

Hard af Segerstad, Y. (2002). Use and adaptation of written language to the conditions of computer mediated communication. Unpublished doctoral dissertation. Goteborg University, Sweden. Abstract [Online] Available: http:/hdl.handle.net/2077/15738

InternetSlang.com/. Retrieved from http://www.internetslang.com/Internet World Stats: Usage and population statistics. [Online] Available: http://www.internetworldstats.com/stats5.htm\#top (statistics updated 30 June 2011)

Mahfouz, S. (2010). A study of Jordanian university students' perception of using email exchanges with native English keypals for improving their writing competency. Computer Assisted Language Instruction Consortium Journal, 27 (2), 393-408.

Meyer, D. (3rd December, 2009). Netspeak won't get you a date. Retrieved from http://blog.mrmeyer.com/?p=5308 Modern American School. [Online] Available: http://www.modernamericanschool.com/inner.php?type=1\&id=27 
NetLingo. Retrieved from http://www.netlingo.com/acronyms.php

Prøysen, S. (2009). The Impact of text messaging on Standard English. Bergen: University of Bergen.

Thurlow, C. (2006). From statistical panic to moral panic: The metadiscursive construction and popular exaggeration of new media language in print media. Journal of Computer-Mediated Communication, 11(3), 667-701. http://dx.doi.org: 10.1111/j.1083-6101.2006.00031.x

Varnhagen, C., McFall, G., Pugh, N., Routledge L., Sumida-MacDonald, H. \& Kwong, T. (2010). lol (sic): new (sic) language and spelling in instant messaging. Reading and Writing, 23 (6), 719-733. http://dx.doi.org:10.1007/s11145-009-9181-y

Weik, P. (2000, June 22). Irbid enters Guinness Book of Records: Internet use flourishes in region. The Star, p. 7.

Yunker, F. \& Barry, S. (2006). Threaded podcasting: the evolution of On-line (sic) Learning". In Dan Remenyi. Proceedings of the International Conference on e-Learning, Université du Québec à Montréal, 22-23 June 2006. Academic Conferences Limited.

Table 1. Students' behaviors in emailing and chatting

\begin{tabular}{|c|c|c|c|c|c|c|}
\hline & Item & always $\%$ & $\begin{array}{c}\text { often } \\
\%\end{array}$ & $\begin{array}{c}\text { sometimes } \\
\%\end{array}$ & $\begin{array}{c}\text { rarely } \\
\%\end{array}$ & $\begin{array}{c}\text { never } \\
\%\end{array}$ \\
\hline 6 & $\begin{array}{l}\text { Checking for grammatical } \\
\text { Correctness when sending } \\
\text { email messages }\end{array}$ & 7.7 & 21.1 & 14.4 & 34.4 & 22.7 \\
\hline 7 & $\begin{array}{l}\text { Checking for spelling mistakes } \\
\text { when sending email messages }\end{array}$ & 7.7 & 15.5 & 22.7 & 32.8 & 21.1 \\
\hline 8 & $\begin{array}{c}\text { Using acronyms and abbreviation } \\
\text { in writing emails }\end{array}$ & 12.2 & 25.0 & 5.5 & 37.8 & 19.4 \\
\hline 12 & $\begin{array}{l}\text { Checking for grammatical } \\
\text { correctness when engaged } \\
\text { in instant synchronous chatting }\end{array}$ & 10.4 & 12.2 & 19.3 & 26.6 & 31.6 \\
\hline 13 & $\begin{array}{l}\text { Checking spelling and punctuation } \\
\text { errors while chatting }\end{array}$ & 8.3 & 11.6 & 16.1 & 29.4 & 34.4 \\
\hline 14 & $\begin{array}{l}\text { Using acronyms and abbreviations } \\
\text { while chatting on the internet }\end{array}$ & 30.1 & 22.2 & 18.3 & 15.5 & 13.9 \\
\hline 15 & $\begin{array}{l}\text { Using emoticons while chatting } \\
\text { on the instant messenger }\end{array}$ & 23.3 & 19.1 & 25.3 & 19.4 & 12.7 \\
\hline
\end{tabular}


Table 2. Students' perception of Internet English

\begin{tabular}{|c|c|c|c|c|c|c|}
\hline & Item & $\begin{array}{l}\text { Strongly } \\
\text { Agree } \\
\%\end{array}$ & $\begin{array}{l}\text { Agree } \\
\%\end{array}$ & $\begin{array}{l}\text { Uncertain } \\
\%\end{array}$ & $\begin{array}{l}\text { Disagree } \\
\%\end{array}$ & $\begin{array}{l}\text { Strongly } \\
\text { Disagree } \\
\%\end{array}$ \\
\hline 1 & $\begin{array}{l}\text { Internet English allows for greater creativity and } \\
\text { expression. }\end{array}$ & 38.8 & 36.6 & 11.1 & 3.6 & 9.4 \\
\hline 2 & $\begin{array}{l}\text { In chatting and emailing, online users make } \\
\text { grammar and spelling mistakes on purpose. }\end{array}$ & 7.7 & 19.4 & 26.1 & 34.4 & 13.3 \\
\hline 3 & $\begin{array}{l}\text { Internet English used in chatting and instant } \\
\text { messaging has a negative impact on English } \\
\text { grammar. }\end{array}$ & 7.7 & 17.2 & 20 & 15.5 & 39.4 \\
\hline 4 & $\begin{array}{l}\text { Internet English used in chatting and instant } \\
\text { messaging has a negative impact on English } \\
\text { spelling and punctuation. }\end{array}$ & 12.2 & 44.4 & 25.5 & 13.3 & 4.4 \\
\hline 5 & $\begin{array}{l}\text { While chatting or emailing, typing speed leads to } \\
\text { errors in the use of English forms. }\end{array}$ & 23.8 & 47.2 & 17.7 & 6.1 & 5.0 \\
\hline 6 & $\begin{array}{l}\text { Internet English is a hybrid of spoken and written } \\
\text { English. }\end{array}$ & 26.1 & 39.4 & 14.4 & 11.6 & 8.3 \\
\hline 7 & $\begin{array}{l}\text { In emailing, chatting and instant messaging, } \\
\text { online users make spelling mistakes due to the } \\
\text { irregularity of English spelling system. }\end{array}$ & 34.4 & 26.6 & 10.5 & 16.6 & 11.6 \\
\hline 8 & $\begin{array}{l}\text { Internet English will develop and upgrade the } \\
\text { English language. }\end{array}$ & 26.1 & 32.2 & 19.4 & 9.4 & 12.7 \\
\hline 9 & $\begin{array}{l}\text { Internet English users pay little attention to } \\
\text { punctuation and capitalization. }\end{array}$ & 17.2 & 39.4 & 8.3 & 20.5 & 14.4 \\
\hline 10 & $\begin{array}{l}\text { Internet English is more rich and dynamic than } \\
\text { regular speech or writing. }\end{array}$ & 25.5 & 18.8 & 23.3 & 21.1 & 11.1 \\
\hline 11 & $\begin{array}{l}\text { In chatting, online users use emoticons to make } \\
\text { others understand them and their personality. }\end{array}$ & 35.5 & 30 & 14.4 & 7.7 & 12.2 \\
\hline 12 & $\begin{array}{l}\text { Using acronyms such as IMHO.BRB, in chatting } \\
\text { and instant messaging saves users' time. }\end{array}$ & 32.2 & 28.8 & 21.1 & 7.2 & 10.5 \\
\hline 13 & $\begin{array}{l}\text { Internet English is almost the same as Standard } \\
\text { English but with slight changes. }\end{array}$ & 24.4 & 27.2 & 11.6 & 29.4 & 7.2 \\
\hline 14 & $\begin{array}{l}\text { Online users use new forms to show they are } \\
\text { modern and not traditional. }\end{array}$ & 34.4 & 31.1 & 18.8 & 9.4 & 6.1 \\
\hline 15 & $\begin{array}{l}\text { Internet English creates new language forms such } \\
\text { as lexical items and acronyms. }\end{array}$ & 27.7 & 37.6 & 12.2 & 14.4 & 7.7 \\
\hline 16 & $\begin{array}{l}\text { Internet users use acronyms and emoticons to } \\
\text { impress their counterparts. }\end{array}$ & 42.2 & 16.6 & 21.1 & 7.7 & 12.2 \\
\hline 17 & $\begin{array}{l}\text { Overuse of slang in chatting and instant } \\
\text { messaging is distorting English. }\end{array}$ & 21.1 & 31.1 & 27.7 & 15.5 & 4.4 \\
\hline 18 & $\begin{array}{l}\text { In chatting and instant messaging, the use of new } \\
\text { forms is indicative of youth, } \\
\text { intelligence and ingenuity. }\end{array}$ & 24.4 & 39.4 & 13.3 & 5.2 & 17.7 \\
\hline 19 & $\begin{array}{l}\text { Internet users misspell words in chatting and } \\
\text { messaging due to typing speed. }\end{array}$ & 21.1 & 42.8 & 17.7 & 9.4 & 8.8 \\
\hline 20 & $\begin{array}{l}\text { In chatting and emailing, users pride themselves } \\
\text { on knowing a specialized language. }\end{array}$ & 22.8 & 42.2 & 17.2 & 10 & 7.7 \\
\hline 21 & $\begin{array}{l}\text { Internet English will create new language } \\
\text { registers not known before. }\end{array}$ & 20.5 & 38.9 & 11.6 & 15.5 & 13.3 \\
\hline 22 & $\begin{array}{l}\text { Online users use acronyms such as IMHO.BRB, } \\
\text { in chatting and instant messaging due to their } \\
\text { deficiency in English spelling. }\end{array}$ & 25 & 33.3 & 9.4 & 21.6 & 10.5 \\
\hline
\end{tabular}

